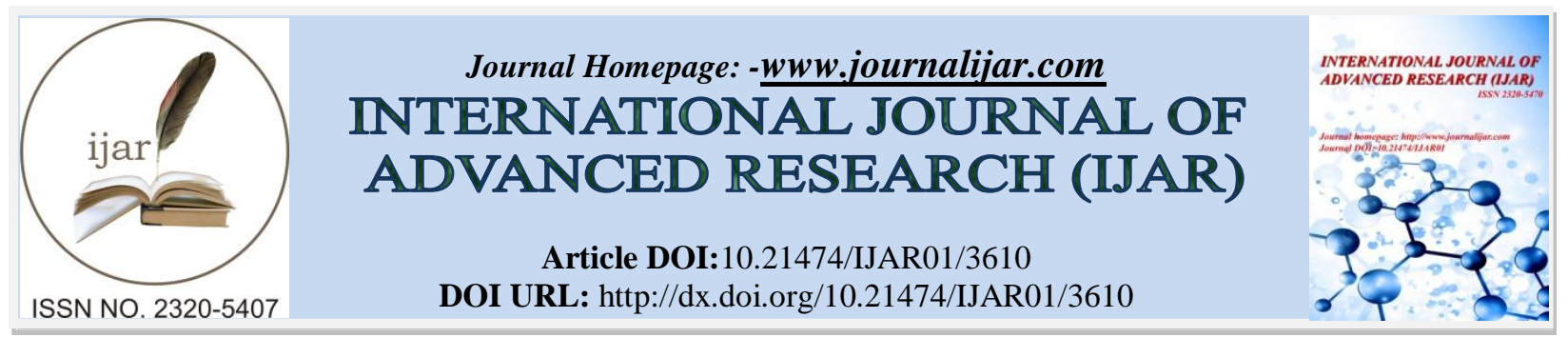

RESEARCH ARTICLE

\title{
NOISE POLLUTION STUDY ATMHASWADYATRAMAHOTSAV, 2016 MAHARASHTRA, INDIA.
}

*Jadhav Sujeet, Pranav Otari and Akshay Mane.

Dept. of Botany, S. B. R. College Mhaswad, Tal. Man, Dist. Satara.

\section{Manuscript Info}

Manuscript History

Received: 07 January 2017

Final Accepted: 08 February 2017

Published: March 2017

Key words:-

MhaswadYatraMahotsav, crackers, noise pollution, monitoring Sites.

\begin{abstract}
The unwanted or disturbing sound is called as noise. This reported study shows noise quality of firing the crackers at "MhaswadYatraMahotsav- 2016", which held every year at Mhaswad, Dist. Satara in Maharashtra. The noise level due to bursting of crackers is measured by using standard method. For present study ten different sites were selected as noise monitoring sites on "Palakhi Marg" and noise of crackers was noted at ten different timings with the interval of half an hour in each recording. The result concluded that, in the residential zone and silence zone at night condition, the noise level exceeded the prescribed standard level of $65 \mathrm{~dB}$ as per the Noise Pollution (Regulation and Control) Rules, 2000.

In the present study, the average noise level at all the recorded timings was found to be above the prescribed limits of Central Pollution Control Board (CPCB).
\end{abstract}

Copy Right, IJAR, 2017,. All rights reserved.

\section{Introduction:-}

Noise pollution is a major concern throughout the world. Noise pollution in different areas is coming from wide variety of sources. Noise is an unpleasant and unwanted sound which is indeed annoying and harmful too. Its effects are more directly on the receiver i. e. Man. It is said that "you may forgive noise but your body will never" (Agrawal and Yadav, 2013).Noise pollution damagingly affects the human being leading to loss of hearing as well as mental stress (Jhanwar, 2016). Although noise pollution is not fatal to human being but its effects cannot be overlooked. Noise causes stress reactions, increased blood pressure, sleep disorders, some hormonal changes and general quality of life (Bhat, 2003). The effect of noise has been studied in humans by different workers(Belojevicet al, 2008; Babisch, 2000 and 2005; Lundberg,1999). At present noise pollution is considered to be one of the key problems that has numerous hazardous effects on environment which deals with cost of society (Martin et al, 2006).

Indian festivals are traditionally celebrated by song and dance in large groups. During festival loudspeakers, bursting of crackers produce intermittent and high frequency impulse noise (Concha-Barrientos et al, 2004). Diwali is an important festival when lot of crackers are used in almost every part of the country (Singh and Joshi, 2010).Mhaswad is famine and low rainy area which is traditionally known for Lord Siddhhnathyatra. This yatra festival is celebrated for one month starting from 'laxmipoojan' of Diwali and ends in kartik month of Marathi year. This yatra is a celebration of marriage ceremony of God Siddhhanath and Goddess Jogeshwari. Traditionally there is a faith that when God and Goddess pass in their "palakhi", citizens are trying to stop that "palakhi" in front of their houses. To stop the "palakhi" peoples are using to burst the fire crackers and thus there is a competition in the peoples for bursting crackers. Traditionally it is called as "Diwali Maidan". 
In the present investigation, an attempt has been made to monitor the noise created by bursting of crackers in "Diwali Maidan".

\section{Working Area:-}

The present work has been carried out at the "Palakhi Marg" at Mhaswad City, Tal. Man, Dist. Satara. This "Palakhi Marg" begins from Shri Siddhanth Temple and passes from main market area and ends back to Shri Siddhanth temple.

\section{Material and Method:-}

The present study was conducted at ten different timings during the "Palakhi Marg" in "Diwali Maidan". The ambient noise level was monitored with the help of sound level meter during $8 \mathrm{pm}$ to $12.30 \mathrm{pm}$. Precaution was taken to avoid echo or resonance of sound by selecting suitable distance from the crackers. Readings were taken after every half an hour interval. Ambient sound levels were compared with that of the standards prescribed in the Environment Act, 1981 and standards of CPCB (Tripathi, 1999). As well as the noise limits given by, The Noise Pollution (Regulation and Control) Rules, 2000 were used to compare the noise levels in areas under study.

Table 1:- Noise standards for ambient noise level

\begin{tabular}{|c|c|c|c|c|}
\hline Sr. No. & Area Code & Category of Area/ Zone & $\begin{array}{l}\text { Sound Level Limit } \\
\text { at Day Time (dB) }\end{array}$ & $\begin{array}{l}\text { Sound Level Limit } \\
\text { at Night Time (dB) }\end{array}$ \\
\hline 1) & A & Industrial Area & 75 & 70 \\
\hline 2$)$ & B & Commercial Area & 65 & 55 \\
\hline 3$)$ & C & Residential Area & 55 & 45 \\
\hline 4$)$ & D & Silence Zone & 50 & 40 \\
\hline
\end{tabular}

Source: Lad et al (2012)

\section{Result:-}

The results of ambient noise pollution monitored in the YatraMahotsav at Mhaswad have been summarized in table 2.

The ambient noise level noted at all the monitored sites was very high as per given by the CPCB. The "Palakhi Marg" is having silence zone, which is also showing ambient noise level more. The highest ambient noise level recorded was 104.2 at 12.30 am which is very high than the recommended noise level at night.

Table 2:-Noise level in different zones of "Palakhi Marg" at Mhaswad city in "Diwali Maidan".

\begin{tabular}{|c|c|c|c|}
\hline Zone & Names of the sites & Time & Sound level (dB) \\
\hline \multirow{3}{*}{ Residential } & \multirow{3}{*}{ Mhaswad Main Peth } & $9.00 \mathrm{pm}$ & 99.2 \\
\cline { 3 - 4 } & & $9.30 \mathrm{pm}$ & 97.5 \\
\cline { 3 - 4 } & & $10.00 \mathrm{pm}$ & 103.4 \\
\hline \multirow{3}{*}{ Silence } & \multirow{3}{*}{ Hospital and Bank } & $10.30 \mathrm{pm}$ & 96.1 \\
\cline { 3 - 4 } & & $11.00 \mathrm{pm}$ & 102.6 \\
\cline { 3 - 4 } & \multirow{3}{*}{ Besidential } & $11.30 \mathrm{pm}$ & 95.9 \\
& \multirow{3}{*}{ BajarPeth } & $12.00 \mathrm{pm}$ & 94.3 \\
\cline { 3 - 4 } & & $12.30 \mathrm{am}$ & 92.7 \\
\cline { 3 - 4 } & & $1.00 \mathrm{am}$ & 98.8 \\
\cline { 3 - 4 } & & $1.30 \mathrm{am}$ & \multicolumn{2}{|c}{} \\
\hline
\end{tabular}


Graph 1:-Showing ambient noise level at different timings during "Diwali Maidan"

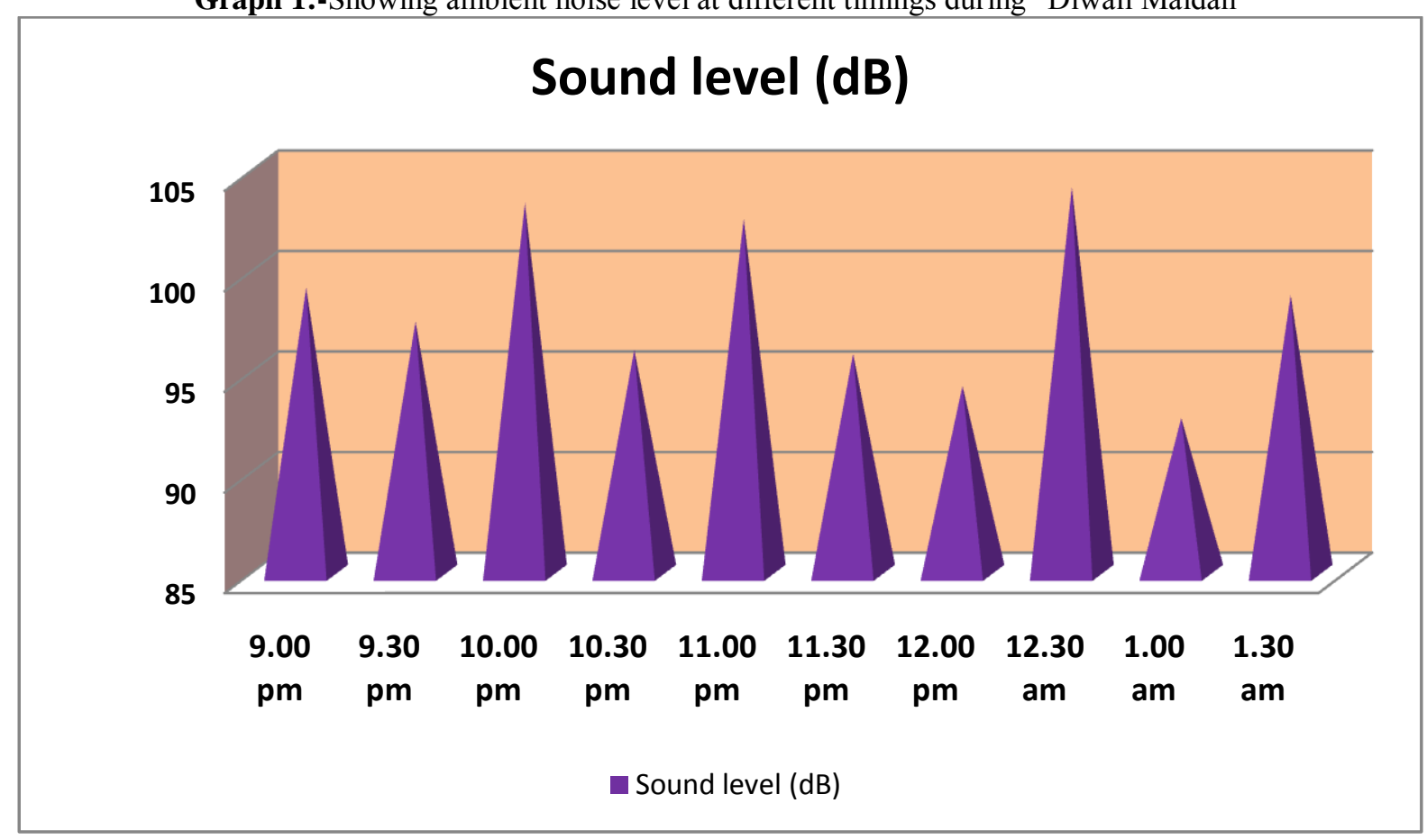

\section{Discussion:-}

In the present study, the average noise level at all recorded timing was $98.47 \mathrm{~dB}$ which is found to be above the prescribed limits of CPCB (Central Pollution Control Board, New Delhi) during the "Yatra Mahotsav" day at 2016. This average recording of ambient noise level at residential and silence zone during night conditions is very high. In the beginning of "Palakhi" noise level is above the average which is slightly declined in the silence zone but again inclined at residential zone at last phase.

According to Mishra et al (2017), the ambient noise level increased due to different human activities during Bhopal VigyanMela 2016.The study report of Patel and Bhave (2014), shows increased noise level due to bursting of crackers during diwali festival. The noise level during festive and non-festive days in Haridwar city were measuredand compared by Sharma and Joshi(2010) which is found to be very high during Diwali season. At different parts of Meerut city on the night of Diwali festive, noise pollution was studied by Singh and Joshi (2010), which shows extreme ambient noise level during Diwali. A study report of Pathak et al (2008) showed traffic noise became main reason of headache, high BP and other stresses among the peoples in the working places at Varanasi city. In Bareilly metropolitan city, the noise level was slightly higher than the prescribed limit of the Central Pollution Control Board (Gangwaret al., 2006).

\section{Conclusion:-}

The present study is an attempt to assess the level of ambient noise pollution during the particular day of "Diwali maidan". Peoples in the residential area were suffered from this high levelled noise pollution. Noise pollution affects and damages the human being leading to loss of hearing as well as mental stress. Efforts are made through this article to make the citizens aware about the preliminaries of noise pollution and its hazardous effects.

\section{Recommendations:-}

$>$ Propersupervision should be followed to make sure that cracker seller in and around Mhaswad, following the noise standards set for crackers.

$>$ There should be ban on noisy crackers during "Yatra Mahotsav" in and around Mhaswad.

$>$ A separate area to be made available to the peoples for firing of crackers by the municipal corporation.

$>$ The time limit should be given for bursting of the crackers which should be strictly followed by the citizens. 


\section{References:-}

1. Agarwal, S. and Yadav, S. (2013).Noise Pollution and Its Impact on Health. International Institute for Science, Technology and Education (IISTE), 3(6).

2. Babisch, W. (2000). Traffic Noise and Cardiovascular Disease, Epidemiological Review and Synthesis, 2(8):932.

3. Babisch, W.(2005). Noise and health, Environ Health Perspective,113(1):A14-15.

4. Bhat, S. (2003). India together: Noisepollution and the law in India. Pp-1-6.

5. Belojevic, G. A., B. D. Jakovljevic,V. J. Stojanov, V. Z.Slepcevic, K. Z. Paunovic(2008). Nighttime roadtraffic noise andarterial hypertension in an urban population.HypertensRes., 31(4):775-781.

6. Bhat, S. (2003). India together: Noisepollution and the law in India. Pp-1-6.

7. Central Pollution Control Acts, rules (1995) and notifications issued there under Pollution Control Series, New Delhi.

8. Concha-Barrientos, M., D. Campbell-Lendrum and K. Steenland (2004).Occupational noise, assessing the burden of deceasefrom work related hearing impairment at national and local levels. Environmental burden disease series, no 9, WorldHealth protection of the human environment, Geneva, 2004.

9. DuringDeepawali festival in Meerut City,Uttar Pradesh.New York Science Journal, ISSN 1554 - 0200 Pp-4041.

10. Gangwar, K. K., B. D. Joshi andA. Swami (2006). Noise pollution status at four selected intersections in commercial areas of Bareilly Metropolitan city, U.P. Him. J Environ Zool.20(1):75-77

11. Jhanwar Deepak (2016).Noise Pollution: A Review, Journal of Environment Pollution and Human Health, 4(3): Pp $72-77$

12. Lad, R.J.,V. N. Patil andP. D. Raut(2012).Study of Noise pollution during Deepawali festival in Kolhapurcity of Maharashtra, India Review Of Research $\mathbf{~ ( V ) , ~ P p . 1 - 4 ~}$

13. Lundberg, U. (1999). Coping with Stress: NeuroendocrineReactions and Implications for Health. Noise Health, 1(4):67-74.

14. Martin, M. A., M. A. Tarrero,A. Gonzaler and M. Machimbarrena(2006).Exposure effect relationships between road trafficnoise annoyance and cost valuations in Valladolid, Spain.Journal of applied acoustics, $\mathbf{6 7}$ (10): 945-652.

15. Mishra, A. A.,Reeta Kori, Nisha Upadhyay, AlokSaxena, P.K. Shrivastava, AnkitaKulshreshthaand Saket Mishra (2017).Ambient Air and Noise Pollution Study at Bhopal VigyanMela 2016, Madhya Pradesh, India.Journal of Environment Pollution and Human Health,5(1):Pp 1-4.

16. Patel, N. L. and Bhave P. P. (2014).Study of noise pollution during deepawali festival.International Journal of Innovative Research in Advanced Engineering (IJIRAE), 1 (6). ISSN: 2349-2163.

17. Pathak, V., B. D. Tripathi, V. K. Mishra (2008).Evaluation of traffic noise pollution and attitudesof exposed individuals in working place.Atmos.Environ.42(16):3892-3898.

18. Sharma and Joshi (2010). Assessment ofnoise pollution during Deepawali festival in asmall township of Haridwar City of Uttarakhand,India. Environmentalist30:216-218.

19. Singh and Joshi (2010).Study of the NoisePollution for three consecutive yearsduring Deepawali festival in Meerut City, Uttar Pradesh.New York Science JournalISSN 1554 - 0200 Pp-40-41.

20. Tripathy, D.B. (1999). Noise pollution.A.P.H. Publishing Corporation, New Delhi. 